\title{
Régis Debray: as tecnologias da crença
}

Juremir Machado da Silva

Dr. Sociologia - Univ. René Descartes, Paris V, Sorbonne Prof. do Programa de Pós-grad. da FAMECOS/ PUCRS
ETERNAMENTE PROVOCADOR, COM um brilho intelectual quase juvenil nos cantos dos olhos, o francês Régis Debray, 57, é um caçador de si mesmo, sempre escapando da sua última imagem para construir outra, fugidia e complexa, à esquerda dos símbolos transformados em clichês. Companheiro de aventuras políticas de Che Guevara, de Fidel Castro, de Salvador Allende e mesmo de François Mitterrand, Debray transitou do marxismo teórico e panfletário de "A Revolução na revolução", texto através do qual Fidel o descobriu nos anos 60, para a prática guerrilheira. Preso na Bolívia, enfrentou a tortura, simulações de execução e foi condenado a 30 anos de prisão. Escapou, em 1970, graças a intervenção de Charles de Gaulle, Jean-Paul Sartre e A ndré Malraux.

Diretor dos "Cahiers de Médiologie", publicados pela Editora Gallimard, Régis Debray rompeu com as estratégias da persuasão para dedicar-se à compreensão dos processos de nascimento e morte das idéias e das ideologias. Maduro, o homem tornou-se refratário às doutrinas e aos dogmas. Não perdeu, entretanto, a malícia do polemista nem a capacidade de síntese do publicista de esquerda. Com uma fórmula, consegue, por vezes, provocar enormes desgastes. A ironia e o paradoxo fazem parte do arsenal desse intelectual, denominação que rejeita por estar implicada na transformação do mundo através das palavras, mais inclinado, na atualidade a falar de Cristo, sem qualquer reverência católica, do que de Louis A Ithusser ou de Chiapas.

A utor de livros importantes como 0 Poder intelectual na França (1989),V ida e morte da imagem: uma história do ol har no 0 cidente (1992), 0 Estado sedutor (1993) e dos seus Cursos de midiologia geral (1994), Debray, formado na tradicional Escola Normal Superior, navega, sem medo dos riscos, nas fron- 
teiras imprecisas da política, da sociologia, da teoria da comunicação e da história. Franco-atirador, nunca poupou críticas ao "terrorismo semiológico" que dominou a França durante as últimas décadas em nome do "tudo é linguagem". Dos velhos tempos, guarda um certa resistência aos Estados Unidos, embora seja um leitor voraz de obras sem fronteiras.

Régis Debray esteve no Brasil, para conferências em Porto Alegre, dias 2 e 3 de setembro, a convite da Faculdade dos Meios de Comunicação Social da PUCRS e da Secretaria da Cultura do Estado do RS. Depois,falou em Brasília, dia 4, na Faculdade de Comunicação da UnB. Finalmente, palestrou na abertura da reunião anual da Intercom, dia 9 de setembro, em Recife. N essas três ocasiões, tratou da midiologia, "disciplina que trata das funções superiores nas suas relações com as estruturas técnicas de transmissão".

N este entrevista, realizada pouco antes de sua ida ao Brasil, instalado em seu confortável e amplo apartamento da rue de l'Odéon, no mesmo edifício onde Thomas Payne escreveu Os Direitos do homem, e ao lado da livraria de Sylvia Beach, amiga e protetora de James Joyce, responsável pela publicação de U lysses, o ex-guerrilheiro, convertido à midiologia, revisou o mito Che Guevara, silenciou sobre Fidel Castro, relativizou o valor das utopias e precisou as suas escolhas políticas.

No seu entender, a dinâmica capitalista precisa de um Estado capaz de redistribuir a riqueza produzida. As novas tecnologias da comunicação, que o fascinam, não servirão, contudo, para implantar uma democracia virtual e universal.

J MS: U m intelectual deve ser julgado pelas suas idéias. 0 senhor, depois de uma trajetória de militante de esquerda e de teórico revolucionário, criou a "midiologia". Q ual a necessidade dessa nova disciplina no universo das ciências humanas deste fim de milênio?

RD: As "idéias" tiveram um papel decisivo ao longo da história humana; é uma banalidade. Como podem signos, veiculados pela imagem, pela fala ou pela escrita, pôr multidões em movimento? Eis o que ainda constitui um mistério para as ciências humanas. $O$ esclarecimento desse fenômenos requer um tipo específico de investigação. A midiologia é a disciplina que se propõe a resolver o enigma da "eficácia simbólica" através do estudo sistemático dos mecanismos de transmissão. Não se trata de uma doutrina, mas de um método de análise. Como exemplos históricos do enigma citado, posso referir-me às religiões e às ideologias. Quando do nascimento do cristianismo, um tal de Jesus, dito Cristo, pronuncia certas palavras. Estas, na seqüência, são transcritas, comentadas, organizadas. Três séculos depois, o império romano torna-se cristão. No ponto de partida da Reforma, um certo Lutero publica, no interior da Alemanha, suas teses. Um século depois, existe uma Europa protestante. Foi-se do impresso aos Estados reformados. Na transformação do marxismo, um certo Marx edita obras de filosofia e de economia política. E faz escola. Resultado final: a URSS, a China e o "comunismo mundial".

A dificuldade da dinâmica transformadora das idéias é o problema do midiólogo (a metade de uma solução). I mporta saber, na esteira de Marx, como "uma idéia se torna força material". E, sobretudo, em que estado se encontra depois disso. A questão de saber por que Jesus, e não Mani da Mesopotâmia ou o deus Mitra, "conquistou as massas" não interessa aos cristãos, mas é justamente o gênero de pergunta que se coloca o midiólogo.

J MS: A midiologia representa uma crítica aos limites da teoria da comunicação, da semiótica e da sociologia da mídia?

RD: Nenhuma das cristalização que acabo de comentar, ou seja, o cristianismo primitivo e o socialismo proletário, faz parte do universo das categorias da comunica- 
ção ou da semiótica. Esta colocou a técnica entre parênteses, enquanto a midiologia estuda em profundidade a relação entre cultura e técnica. Além disso, a fé no Cristo ressuscitado não foi transmitida pelo jornal, assim como o marxismo não o foi pelo telégrafo. Os seus meios de constituição ultrapassam por todos os lados o que chamamos hoje de meios de comunicação. Mediação não é mídia. Classificar a midiologia como "media studies" seria tão perspicaz quanto situar o estudo do inconsciente nas ciências ocultas. Em midiologia, distinguese a transmissão, ou transporte da informação no tempo, da comunicação, transporte da informação no espaço. As duas não são separáveis, mas a transmissão histórica parece-me ao mesmo tempo mais ampla e profunda do que a comunicação social, com seus esquemas do tipo emissor - meio - receptor.

O interessante é que o objeto de uma transmissão não existe antes desta. Cristo nasceu no terceiro século, não no primeiro. A ntes, só existia o Jesus de Nazaré. Foram precisos três séculos de elaboração cultural para construir a figura do Messias. Isso é mais apaixonante, tudo mundo concordará, do que a influência das telenovelas sobre a juventude. Mesmo que possa exercer em paralelo uma midiologia das religiões e uma sociologia da mídia, esta me interessa muito menos.

J MS: A midiologia não seria apenas um projeto pessoal?

RD: A midiologia é um esporte de equipe, como o futebol e não deve ser tratada como um capricho individual. Tratase de um campo coletivo do qual participam numerosos pesquisadores, alguns ligados à revista $\mathrm{C}$ ahiers de médiol ogie. Obviamente, havia um coeficiente pessoal na minha própria pesquisa. É normal que um "intelectual revolucionário", convencido de produzir mudanças através de palavras, questione-se a partir de um certo momento sobre a maneira das palavras agirem sobre as coisas. A eficiência simbólica é o pão de cada dia do militante intelectual. É lógico que este se pergunte como uma representação do mundo pode modificar a situação desse mundo. Como uma idéia toma corpo na sociedade? Para compreender isso, é preciso, creio, inverter o curso habitual da história cultural. Não se trata mais de decifrar o mundo dos signos, mas de compre ender-Ihes o seu "tornar-se mundo". Como a palavra do profeta torna-se Igreja, seminário, Escola, manifesto, Partido? Em resumo, de que maneira forças simbólicas convertem-se em forças estabelecidas?

Acho que a resposta passa pelo estudo das "tecnologias da crença", isto é, das vias pelas quais as "idéias" se disseminam e se encarnam. Vasto campo de análise transversal a várias disciplinas. Esse gênero de curiosidades, vê-se bem, estava na contramão do espírito individualista, libertário e "nietzschiano" que dominou o pensamento francês nos anos 60 e 70, com Foucault, Deleuze, Lyotard, etc. As minhas reflexões e dúvidas diziam respeito aos fundamentos da coesão social e da instituição, assim como sobre os efeitos da ortodoxia e da totalidade: a nação, o religioso, a fronteira, o sagrado. Por isso, publiquei, em 1981, minha Crítica da razão política.

J MS: Para entrar no coração da midiologia, cruzamento do material, do político e do simbólico, o senhor costuma falar numa história dos quatro " $M$ ". Q ue significa isso?

RD: Os quatro " $M$ " representam os quatro estados sucessivos, as quatro etapas do percurso midiológico: mensagem, mé dium, meio e mediação. " $M$ " de mensagem, como militância, messianismo, ministério. " $M$ " de médium, como memória, material, maquinaria, monumento. " $M$ " de meio, como mundo, modo, macrossistema técnico, média (onda), "in medio stat virtus". " $M$ " de mediação, como mistura, maldição ou milagre. Cada degrau está imbricado no precedente, como um "zoom" retrospectivo através do qual se iria do condicionado 
à sua condição de existência em busca de mais inteligibilidade. Assim, a ordem de exposição inverte, neste caso, a ordem dos fatores. A mensagem remete a uma pragmática; o médium, a uma tecnologia; o meio, a uma ecologia; a mediação, por fim, a uma antropologia. Cada parada no caminho supõe uma mudança de escala cronológica e espacial: a mensagem individual tem um momento, "hic et nunc"; o médium utilizado pertence a uma época; o meio, continental, é uma sedimentação secular; e a mediação é multimilenar, própria à espécie "sapiens-sapiens", trans-histórica.

J MS: H omem de ação e de idéias, como se pode ver, o senhor participou da luta armada na A mérica Latina e serviu de guru para Fidel Castro e Che Guevara. Intelectual, a midiologia é 0 seu campo de pesquisa e de paixão. Como o se nhor de define, hoje: guerrilheiro marxista arrependido ou pensador capaz de conceber projetos para um futuro melhor?

RD: O "ou" da pergunta é desnecessário. $O$ intelectual trabalha e o cidadão engaja-se. A mbos podem coexistir no mesmo indivíduo, mas o cidadão não deveria ter o direito de usar a sua notoriedade intelectual ou de mídia para impor aos outros as suas escolhas. Deixemos a guerrilha de lado. Eu tinha 25 anos; estou agora com 57, e vivo na Europa. Eu me engajei civicamente contra o Tratado de M aastricht, contra a Guerra do Golfo, em defesa dos valores republicanos face ao neoliberalismo, contra a arrogância imperial dos Estados Unidos que pretendem impor a sua legislação interna ao mundo inteiro. Mas tudo isso à margem do meu trabalho de filósofo e de midiólogo. Não julgo o valor literário ou teórico de uma obra em função das opções políticas do autor. Peço que assim ajam os outros em relação a mim. O resto não me interessa.

J MS: 0 seu amigo Che Guevara tornouse mito e objeto nas mãos dos comerciantes de "gadgets". Q ue sentimento Ihe provoca esta apropriação da imagem de um revolucionário? D e resto, quem foi realmente Che Guevara: um herói romântico, encarnação política de Rimbaud, ou um militantefrio e mau estrategista militar traído por Fidel Castro?

RD: Quem foi Che? Os documentos abundam etransbordam. Mais uma sombra no quadro. Que foi feito do Che, o que ele se tornou? Em que espécie de espectro se transformou esse morto? Eis o problema crucial para nós: em que se transformam as idéias e os homens excepcionais depois que se vão deste mundo? O que acontece com os grãos expostos ao ar do tempo? Passemos rapidamente pela questão mercantil. Hollywood devora tudo. Pôsteres, cartazes, fotos, filmes: a videosfera converteu um iconoclasta em ícone. $\mathrm{O}$ homem das sombras, refratário às câmaras e aos microfones, tornou-se "visual", exposto por toda parte. Entramos num mundo no qual a fé conta menos do que o crente, no qual a doutrina desaparece sob o mártir de carne e osso. A encarnação tomou o lugar do Verbo; a entonação salva o discurso. A utopia comunista voltada para o futuro transforma-se em narração do passado, em "roadmovie".

Isso, ao menos, prova que a causa pode renascer depois do enterro do partido. Os fracassos revolucionários, desde a Comuna de Paris, são como bombas-relógio, deflagrações "à posteriori". Impossível evitar a irritação diante da "Chemania", da redução de um ser rigoroso, no qual se aliavam um máximo de pensamento e um máximo de rebelião, a uma espécie de Robin Hood mesclado com James Dean, rebelde simpático mas sem causa precisa. Cabe perguntar se Hollywood e a Disneyland vão, finalmente, transformar tudo em superprodução, inclusive os que se insurgem contra o Império e os assassinados do Império. A té aonde irá a nova divisão do trabal ho entre o Norte comunicador e o Sul sofredor. O Sul entra com os mortos; o Norte faz os filmes.

Pode-se, no entanto, ol har as coisas 
pelo lado bom. Dá, por exemplo, para apostar na sobrevivência de certas figuras, através da lenda, a soma de contra-senso que faz sentido, como testemunho da profunda insatisfação em relação à situação de nosso planeta convertido em supermercado. Há em toda sobrevivência o indício de uma energia espiritual intacta, de uma vontade de não arquivar o "dossiê capitalismo" para sempre. Que a esperança consiga sobreviver às suas ruínas. É uma mensagem de encorajamento, não?

JMS: Nos seus "M anifestos midiológi$\cos ^{\prime \prime}$, o senhor diz que o mundo passou da logosfera à videosfera, ou seja, a era da imagem. 0 Poder "transformador" da escrita foi engolido pela sedução vazia das telas?

RD: Nada engole nada. Não sejamos simplistas nem ingenuamente evolucionistas. As midiasferas sucedem-se entreme ando-se. A imagem submete a escrita, mas não a faz, de modo algum, desaparecer. A oposição escrita/tela não é séria. Todo mundo sabe que a tela informática oferece textos em profusão. Além disso, não podemos esquecer o efeito "jogging" do progresso técnico. No começo deste século, certos futuristas previam que o uso imoderado do automóvel pela população urbana provocaria a atrofia dos membros inferiores das pessoas; o bípede motorizado perderia o hábito de caminhar. $\mathrm{Na}$ realidade, o que se viu? Depois que os citadinos não caminham mais, eles correm. Fanaticamente. Nos parques ou, na falta destes, em salas, em esteiras. Quanto mais o longínquo se aproxima, mais somos levados a explorar os seus contornos. Cada novo veículo, longe de eliminar o território anterior, tende a revalorizá-lo. Conectado ao ecossistema terrestre, cada um saltita no seu ninho. "Small is beautiful". Não se pode uniformizar de um lado sem provocar, de outro, uma bal canização.

Exemplo: o esporte globalizado. O etnocentrismo caricatural que caracteriza as retransmissões de rádio e de televisão do
Mundial de futebol é o saldo da "grande festa universal". As Olimpíadas celebram a religião sem fronteiras dos corpos, paródia muscular da Religião da Humanidade de Auguste Comte. Cada nação vê a sua parte e nenhuma vê o todo. A grande missa eletrônica é instantaneamente nacionalizada através do comentário e do enquadramento das câmaras exclusivas. Tudo acontece como se a mundialização dos objetos e dos signos provocasse uma tribalização dos assuntos e dos valores.

J MS: 0 mundo intelectual foi sacudido, há dois anos, pelo "caso Sokal", denúncia da suposta impostura do pensamento francês contemporâneo. É bem verdadeque Pierre Bourdieu ocupa cada vez mais espaço atacando a mídia, embora Olivier Mongin, diretor da revista "Esprit", acuse-o de populista. 0 senhor lamenta o desaparecimentos dos "maîtres à penser" como Sartre e considera que a França atravessa um vazio intelectual?

RD: Os políticos franceses praticam um excelente hábito, o qual poderia ser seguido por artistas e intelectuais: nunca evocar questões de política interior no estrangeiro. Nós, intelectuais, deveríamos evitar de abordar nossas diferenças e acertar nossas contas fora de nossas fronteiras. Se abordo, na França, os meus desacordos, que são consideráveis, com Pierre Bourdieu ou com outros, todos podem tomar conhecimento dos meus argumentos e responder conforme a regra do jogo. Falar mal deles no Brasil, nas costas deles, não é "fair-play". De resto, as polêmicas pessoais cansam-me. Quem luta contra alguém acaba, obrigatoriamente, por assemelhar-se ao adversário. A personalização do debate de idéias faz certamente parte do jogo da mídia, inclusive da imprensa intelectualizada, pois a política das personalidades sempre vende mais. Mas essa personalização nunca serviu para aprofundar a inteligibilidade do mundo.

J MS: Outros países, como os Estados 
Unidos, a A lemanha e a Inglaterra, têm, atualmente, uma produção intelectual mais consistente?

RD: Os universos intelectuais comunicam-se raramente entre eles; o fluxo das traduções segue a linha de menor resistência ou de mais forte declive. As obras ou nomes mais facilmente passíveis de exportação são geralmente os menos originais ou os de mais simples acesso; logo, mais fáceis de traduzir e de compreender. O maior pensador francês do século XX chama-se André Leroi-Gourhan. Paleontólogo e especialista da pré-história, escreveu a mais admirável síntese existente sobre a evolução humana, 0 Gesto e a palavra, publicado em 1964. Suponho que pouca gente tenha ouvido falar dele no estrangeiro. Não me sinto, portanto, capaz de julgar a produção inglesa, alemã ou americana a partir do que conhecemos em Paris.

A fúria semiótica e o "tudo é linguagem" das últimas décadas não favoreceram na França as pesquisas sobre as tecnologias simbólicas. Não surpreende, portanto, que dois terços da minha biblioteca de midiólogo sejam em inglês.

Dela fazem parte Harold Innis ("se a Primeira Guerra Mundial pode ser vista como um 'clash' entre o jornal e o livro, a Segunda foi um 'clash' entre o jornal e o rádio"), McLuhan, claro, Raymond Williams, Elisabeth Einseinstein, Benedict Anderson, Walter Ong, Robert Darnton, Eric Havelock, Jack Goody, N eil Postman e chego a esquecer os demais. É certo que eles aparecem depois de Walter Benjamin, o alemão de Paris que teve a boa idéia de perguntar, não se a fotografia era uma arte, mas o que ela mudou em nossa prática da arte.

O terço restante (a cada um as suas limitações) é formado pelos escritores de meu país, os quais sempre me deram mais do que os nossos teóricos, de Diderot a Valéry, passando por Balzac, Hugo e Mallarmé. Romancistas e poetas tem um "flair" particular para detectar o infima- mente crucial. Balzac, por exemplo, compreendeu prontamente o que estava em jogo na passagem do papel feito a partir de restos de tecido ao papel originário da madeira: a democracia de opinião, com seus jornais e cartazes. Valéry anunciou "as sociedades de distribuição de realidade a domicílio", muito antes do aparecimento das nossas redes de televisão.

Esquecemos em demasia o senso prático e o instinto de observação dos escritores, o que lhes permite de descobrir o novo sem o formalizar.

J MS: Crítico implacável do estruturalismo, o senhor ridicularizou a idéia segundo a qual tudo é texto, tudo é signo, tudo é linguagem. $\mathrm{N}$ inguém foi poupado, de Barthes a $\mathrm{H}$ abermas, passando por Jacques Lacan, U mberto E co e Julia K risteva. 0 pensamento francês, principalmente, dos últimos trinta anos foi vítima de um gosto exagerado pelas fórmulas de efeito, tais como a "morte do homem" ea "morte do autor"?

RD: Integro o movimento coletivo de renovação materialista, o qual desloca o foco das idéias na direção das coisas e globalmente no sentido da cultura material. Houve uma inflação semiológica que levava a pensar que todas as coisas nos faziam sinal. Com isso, esqueceu-se que os signos também são coisas. As imagens possuem um suporte. Interessa-me entrar no conteúdo vivo dos elementos, nos materiais, nas técnicas de produção dos símbolos.

JMS: 0 senhor acredita que Roland Barthes e os seus amigos conseguiram transformar o "ilegível" em critério superior de qualidade literária e a au sência de comunicação em condição "sine qua non" da existência de arte?

RD: Assim como Marcel Duchamp não é responsável pelo conformismo conceitual dos que se dizem, nos últimos 50 anos, seus seguidores, Roland Barthes nada tem a ver com os discursos pseudoteóricos caraterísticos dos seus discípulos em literatura. Durante toda a sua vida, 
Barthes impulsionou e foi impulsionado pela voga Saussuriana, a qual, a partir da lingüística imaginava poder construir uma teoria científica do homem. No fim da sua vida, Barthes rompeu suavemente com essa ilusão cientificista e produziu as duas mais belas obras suas, verdadeiras demonstrações de retorno ao prazer da transparência e ao silêncio do prazer estético. Penso em Câmara clara e Fragmentos de um discurso amoroso. Pode-se perfeitamente destruir o teórico Barthes com ajuda do Barthes escritor. Prefiro, evidentemente, o segundo.

J MS: No campo das novas tecnologias da comunicação, os franceses dividem-se entre 0 pessimismo de Paul Virilio, Lucien $\mathrm{Sfez}$ e Jean Baudrillard e o otimismo de Pierre Lévy. Para 0 senhor, Internet é mais um instrumento de comunicação à disposição dos usuários ou a cristalização de uma revolução social, cultural e cere bral capaz de estabelecer uma nova maneira de aprender, de conhecer, de viver em comunidade e de gerar uma democracia virtual?

RD: A resposta exigiria muito espaço e reflexão. N esse tipo de situação e de matéria, existem sempre os apocalípticos e os críticos, retomando, de certa maneira, os termos de Umberto Eco. Os apocalípticos fazem muito barulho e conquista uma grande fatia de mercado, pois os homens parecem ter necessidade de sentir medo e o anúncio de grandes catástrofes é uma constante da futurologia, embora regularmente desmentida pela ironia da história. As ferrovias não trouxeram nem a paz mundial como acreditava Victor Hugo nem asfixiaram a humanidade dentro de túneis como temia A rago.

A técnica é importante, mas sempre menos grave do que se crê. Internet é um entusiasmante fator de aceleração do saber e de esfacelamento anárquico das pirâmides autoritárias, mas os que esperam da cibercultura a democratização do planeta correm o risco de uma enorme decepção. De toda maneira, não coloco no mesmo ní- vel meu amigo Pierre Lévy, otimista crítico e sutil, e os profetas superficiais da catástrofe.

JMS: 0 senhor era próximo de François $M$ itterrand. $H$ oje, a França vive, sob a co-habitação esquerda/direita de Lionel Jospin/Jacques Chirac, uma espécie contraditória de social-democracia liberal. Para muitos marxistas, Jospin, como Tony Blair, na Inglaterra, representa a face escondida do neoliberalismo. Para muitos liberais, ao contrário, trata-se como sempre de um defensor do Estado-providência. Q ue papel deve cumprir um partido de esquerda para corresponder ao seu passado histórico de esquerda, enfrentar as especi-ficidades do presente e trabalhar por um futuro socialmente menos injusto?

RD: E se parássemos com a "demonização" da política e do adversário? Na verdade, este assunto já não me interessa muito. Se mantenho as minhas convicções de homem de esquerda, demiti-me do ConseIho de Estado já faz muito tempo e abandonei todas as funções administrativas, políticas ou militantes há dez anos. Farei simplesmente uma observação de bom senso.

O mercado cria riquezas, mas não pode redistribuí-las. Para isso, é necessário um Estado que não se confunda com as forças do capital.

Sem uma ação política, corajosa e voluntarista, a dinâmica do mercado converte-se em ditadura do mercado em todos os setores da vida. Isso é o que se precisa evitar. Mesmo se a esquerda democrática tem uma certa tendência excessiva para as falsas facilidades liberais, ainda assim é ela que me parece mais bem colocada para aplicar um programa mínimo: economia mista, defesa dos serviços públicos, redistribuição fiscal e proteção das exceções culturais.

J MS: A s utopias, pertencentes por definição ao universo do movimento, podem tornar-se reacionárias ao não aceitar, de acordo com as particularidades de cada época histórica, a redefinição dos seus objetivos iniciais? 
RD: Esperava-se Jesus Cristo; veio a Igreja. Esperava-se o proletariado; veio o partido. Esperava o partido; o secretáriogeral devorou-o, etc. As utopias, como a língua de Esopo, são a melhor e a pior das coisas. As utopias seculares, sem dúvida, preencheram o vazio religioso do século passado; o declínio da utopia progressista traduziu-se imediatamente pelo crescimento dos integrismos religiosos. Não se pode brincar ou recorrer a astúcias com a natureza religiosa do homem. Tudo o que podemos fazer, em síntese, é buscar um religioso de menor custo político e intelectual. Mas certamente não se trata do futebol ou da televisão. Tampouco não se trata da fuga para o Tibet, segundo um orientalismo de pacotilha. Entre o ópio do povo e o incenso dos quadros dirigentes, acabaremos por descobrir uma terceira via. Pessoalmente, a República como mística me convém bastante bem. Sou orgulhosamente um filho de Auguste Comte.

J MS: Comemorou-se em 1998 os trinta anos de maio de 1968. 0 senhor sempre foi muito crítico em relação ao mito da primavera de Paris. Por quê?

RD: Há 20 anos, no meu pequeno livro M odesta contribuição para os discursos e cerimônias do décimo aniversário propus uma leitura ímpia de maio de 68 como revolução liberal e individualista ou a virada da esquerda rumo à direita, ou, ainda, caso se prefira, a entrada da China maoísta na A mérica capitalista. Essa análise, evidentemente na contramão, pareceu totalmente absurda na época, em 1978. Hoje, ela se tornou um clichê na "intelligentsia" jornalística francesa. Chego a sentir vontade, agora, de encontrar coisas positivas para dizer sobre o maio de 1968 dos parisienses, o qual, infelizmente, não vivi, pois, naquele período, eu estava na prisão.

É sempre reducionista de julgar um fenômeno social pelo seu resultado histórico, pois em história, o resultado é, na maior parte do tempo, o contrário das intenções.
Como dizia Victor Hugo, “todas as histórias de pássaros terminam num gato". Mas isso não deve matar o nosso desejo de voar, ao menos de tempos em tempos .

\section{Nota}

Adaptação de entrevista publicada pela Folha de S.Paulo, em 30 de agosto de 1998, no Caderno M ais. 